The University of San Francisco

USF Scholarship: a digital repository @ Gleeson Library | Geschke Center

Nursing and Health Professions Faculty Research and Publications

2014

\title{
Disseminating an Evidence-Based Course to Teach Self-Management of Auditory Hallucinations
}

M Buffum

Robin Buccheri

University of San Francisco, buccherir@usfca.edu

L Trygstad

G Dowling

Follow this and additional works at: http://repository.usfca.edu/nursing_fac

Part of the Nursing Commons, and the Psychiatric and Mental Health Commons

\section{Recommended Citation}

Buffum M., Buccheri R., Trygstad L., Dowling G.(2014). Disseminating an Evidence-Based Course to Teach Self-Management of Auditory Hallucinations. J Psychosoc Nurs Ment Health Serv. 52(4) 32-41. doi: 10.3928/02793695-20131029-04

This Article is brought to you for free and open access by the School of Nursing and Health Professions at USF Scholarship: a digital repository @ Gleeson Library | Geschke Center. It has been accepted for inclusion in Nursing and Health Professions Faculty Research and Publications by an authorized administrator of USF Scholarship: a digital repository @ Gleeson Library | Geschke Center. For more information, please contact repository@usfca.edu. 


\title{
Disseminating an Evidence-Based Course to Teach
}

\section{Self-Management of Auditory Hallucinations}

\begin{abstract}
This multi-site project extended course dissemination of the 10-Session Behavioral Management of Auditory Hallucinations Course to Department of Veterans Affairs (VA) mental health outpatient settings. The VA Quality Enhancement Research Initiative (QUERI) model and Rogers' theory of diffusion of innovations served as the theoretical framework. The course was taught to mental health professionals using teleconferencing, electronic media and monthly conference calls across 24 VA mental health outpatient sites. Twenty course leaders provided feedback. One hundred percent reported being better able to communicate with patients about their voices and 96 percent reported improved understanding of the voice hearing experience. Thirty-three course participants provided feedback. Ninety-four percent would recommend the course, 85 percent reported being better able to communicate with staff about their voices and 66 percent reported being better able to manage their voices and felt less alone with their voices. Facilitators and barriers to course implementation are described.
\end{abstract}




\section{Disseminating an Evidence-Based Course to Teach}

\section{Self-Management of Auditory Hallucinations}

The 10-Session Behavioral Management of Persistent Auditory Hallucinations Course has demonstrated significant patient benefits (improvement in negative characteristics and intensity of auditory hallucinations $(\mathrm{AH})$ and reduction in harm commands, anxiety and depression) in multiple investigations (Buccheri et al., 2004; Trygstad et al., 2002; Buccheri, Trygstad \& Dowling, 2007; Buffum, Buccheri, Trygstad, Gerlock, Birmingham, Dowling et al., 2009). This course offers nurses, psychologists, psychiatrists and social workers interactive skills for teaching patients to self-manage unpleasant $\mathrm{AH}$ including harm commands.

Disseminating this course widely into mental health practice is the current crucial challenge in order to optimize health outcomes for those suffering from unpleasant $\mathrm{AH}$ and harm commands. Building on findings from our previous work and applying Rogers' (2003) diffusion of innovations theory and the Veterans Affairs (VA) Quality Enhancement Research Initiative (QUERI), this project expanded dissemination of the course. The purposes of this article are: a)

to describe steps taken to expand dissemination of the 10-session course to multidisciplinary mental health care clinicians in VA mental health outpatient settings and b) to present feedback data from both course leaders (mental health clinicians) and course participants (patients).

\section{Background}

The authors' past work includes dissemination of the 10 -session course in six VA inpatient and outpatient sites with advance practice nurse (APN) course leaders (Buffum et al., 2009). Influential factors favoring staff adoption included support from the dissemination team, flexible adaptation, knowledge about teaching the course and improving interaction with patients about their $\mathrm{AH}$, and gratification from observed patient benefit. 


\section{Theoretical Framework}

The VA Quality Enhancement Research Initiative (QUERI) model of dissemination of evidence-based practice and Rogers' theory of diffusion of innovations guided this project. Both models are described below.

\section{QUERI Model}

The VA developed the QUERI model for dissemination of evidence-based practice throughout VA healthcare. There are three critical components of successful implementation of the QUERI model: 1) partnership of project researchers and clinicians, both of whom ensure that translation into practice is based on the most current and strongest evidence and evaluation of outcomes; 2) facility-based leadership that helps create an organizational culture with the necessary infrastructure, support, and sustained enthusiasm for implementation of the innovation; and 3) evaluation of effectiveness of translation, demonstrated by providers' adoption, fidelity/consistency of delivery of the innovation, and improved clinical patient outcomes (Stetler, McQueen, Demakis, \& Mittman, 2008; Fortney al., 2012).

\section{Rogers' Theory of Innovation Diffusion}

Rogers' (2003) theory of diffusion of innovations describes adoption of an activity as a function of both the people and the innovation. Opinion leaders, those with strong influence and credibility, are essential for successful adoption of a new activity. Changing practice requires opinion leaders who can convince team members about the advantages of an innovation. Even with opinion leaders, individuals' paces of learning and accepting change vary. Team members undergo a five-stage behavioral process to arrive at a decision about whether or not to change practice. The five stages are: 1) knowledge -- learning about a proposed activity; 2) persuasion -- developing a positive attitude about the proposed activity and sharing it with others; 3 ) 
decision -- making the decision to begin trying the new activity; 4) implementation -- actually testing the new activity and adapting it to the setting; and 5) confirmation -- deciding that the testing was sufficient for keeping, rejecting, or delaying adoption of the new activity (Rogers, 2003). A description of Rogers' stages in this dissemination project are described in Table 1.

Adoption of the innovation, or new clinical practice, also depends on several characteristics of the innovation. Influential characteristics of the innovation that make adoption more likely include: a strong evidence base, compatibility with the clinician and organizational values (e.g., treatment has demonstrated patient benefit), understandability with ease of testing, modifiability, and observable benefits (Sanson-Fisher, 2004).

\section{Study Objectives}

The objectives of this project were to: a) educate multidisciplinary mental health clinicians to become course leaders and teach the 10 -session course and b) evaluate feedback from course leaders and course participants.

\section{Methods}

\section{Design}

This multi-site project disseminated and evaluated the implementation of an evidencebased clinical innovation across 24 VA mental health outpatient settings.

\section{Clinical Innovation}

The 10-Session Behavioral Management of Auditory Hallucinations Course is an evidence-based innovation for clinicians to teach patients how to self-manage unpleasant $\mathrm{AH}$ (Buccheri, et al., 2006; Buccheri, et al., 2004; Trygstad, et al., 2002; Buccheri, Trygstad \& Dowling, 2007). The Treatment Manual: Guidelines for Teaching the 10-Session Behavioral Management of Auditory Hallucinations Course (Buccheri, Trygstad, \& Buffum, 2010) provides 
course leaders with process, content, instruments and feedback/evaluation forms. The strategies to self-manage AH taught in the course are listed in Table 2.

\section{Sample}

Course leaders. Course leaders were recruited at 3 national conferences for VA mental health professionals. The project trainers, who are the original researchers, presented a 30minute overview of outcomes from past studies about the 10-session course at the conferences. Those interested in learning more about teaching the course then attended a 90-minute workshop. This interactive workshop included information about course process and content followed by a question and answer period about feasibility issues for conducting the course and customization for specific settings. Following the 90-minute workshop, interested attendees provided their contact information to the project trainers. Subsequently the project trainers contacted all interested attendees by email and requested confirmation of interest in participating in the project.

Twenty-four mental health clinicians at 24 VA mental health outpatient sites across the U.S. took the training and became course leaders. These course leaders included two advance practice nurses, three staff nurses, 11 social workers, seven psychologists, and one vocational rehabilitation specialist. The role of course leader was to coordinate activities at their respective sites to enable them to teach the course (e.g., obtain administrative approval, involve staff, recruit patients to become course participants).

Course participants. Patients were recruited from their sites' existing mental health programs. Some sites already had methods for announcing classes in their recovery programs such as monthly postings of the schedule of classes or flyers for announcing new additions. Other sites needed assistance developing strategies for recruitment. The project trainers 
provided a sample flyer (Figure 1). Course participants were those patients who self-selected to attend because they heard voices and wanted to learn strategies to manage them.

\section{Procedures}

Institutional approvals. Prior to the collection of any data, the following institutions approved this project: San Francisco Veterans Affairs Medical Center Research and Development Committee; University of California, San Francisco, Committee on Human Research; and University of San Francisco, Institutional Review Board for the Protection of Human Subjects. Feedback forms submitted to project trainers contained no individual identifiers.

Training. Mental health clinicians interested in becoming course leaders received an information letter (i.e., describing the project, their roles and risks and benefits of their participation). They also received the Treatment Manual: Guidelines for Teaching the 10Session Behavioral Management of Auditory Hallucinations Course (Buccheri, Trygstad, \& Buffum, 2010), a training DVD and a relaxation CD for use in the course.

Course leader training consisted of a one and one half-hour teleconference call to review and answer questions about the Treatment Manual. This was followed by four monthly one-hour interactive problem-solving teleconference calls. Topics discussed during these calls included issues such as obtaining administrative approval to teach the course, recruiting course participants, and dealing with paranoid and delusional communication among course participants.

Project trainers encouraged email communication with course leaders, interactive discussions on calls and emails, and ongoing feedback about adaptation in individual settings. 
Examples of course adaptations included teaching a strategy more than once and teaching the course multiple times.

Instruments. There were three instruments and one safety protocol used as course tools in teaching the 10-session course and two outcome measures used to collect course leader and course participant feedback. These instruments are described below.

\section{Instruments used as course tools.}

The Auditory Hallucinations Interview Guide (AHIG) is an investigator-developed 59item instrument course leaders used to interview course participants either before or during the 10-session course. This interview guide has yes/no and open-ended questions about the circumstances surrounding onset of $\mathrm{AH}$, current and past experience with $\mathrm{AH}$ and what helps manage AH (Buccheri, Trygstad, Buffum, Lyttle, \& Dowling, 2010; Buccheri, Trygstad, Buffum, Birmingham \& Dowling, manuscript accepted for publication; Buccheri, Trygstad \& Dowling, 2007).

The Characteristics of Auditory Hallucinations Questionnaire (CAHQ) is a 7-item Likerttype instrument on which patients rate characteristics of their AH (frequency, loudness, control, tone, clarity, distractibility and distress) during the past 24 hours on a scale of 1 to 5 , with higher scores indicating more negative characteristics of AH. Test-rest reliability estimates for the CAHQ range from 0.73 to 0.78 ( $\mathrm{p}<0.001$ ) (Buffum, et al., 2009).

The Unpleasant Voices Scale (UVS) is a 7-item investigator-developed scale that asks course participants to rate the intensity of their unpleasant voices on a scale of 0 (no voices heard) to 10 (the most unpleasant your voices could be) during the past 24 hours and past week; the UVS also asks whether they hear pleasant voices, commands to harm, and intent to act on 
those commands (Buccheri et al., 2007; Buccheri et al., 2010; Buffum et al., 2009; Gerlock, Buccheri, Buffum, Trygstad, \& Dowling, 2010).

Accompanying the UVS is the Safety Protocol: Protocol Response to Intent to Harm Self or Others that enables a rapid and scripted assessment of intent to act on commands to harm self or others. This protocol is utilized if course participants respond on the UVS that they hear commands to harm self and/or others and intend to act on those commands. This safety protocol has demonstrated clinical feasibility and utility in keeping course participants and others safe (Buffum et al., 2009; Gerlock, Buccheri, Buffum, Trygstad, \& Dowling, 2010).

\section{Instruments used to collect feedback.}

The Course Leader Feedback Form is a 5-item investigator-created instrument for completion after teaching the course. The first four questions each request a yes/no response about perceived skill changes after teaching the course. The fifth question is open-ended and asks for suggestions for course improvement.

The Course Participant Feedback Form is a 5-item, investigator-created instrument for completion after participation in the course. All questions request a yes/no response about perceived changes after attending the course and willingness to recommend the course to others.

\section{Data Analysis}

Frequencies were calculated for categorical data on both evaluative feedback forms. Content analyses were done to determine themes from e-mail communications, teleconference discussions and write-in suggestions on the course leader feedback forms.

\section{Results}

Course leader attendance in the conference calls was as follows: all 24 course leaders $(100 \%)$ participated in the first two teleconference calls; $20(83 \%)$ participated in the third call; $11(48 \%)$ participated in the fourth call; eight (33\%) participated in the fifth call; and eight (33\%) 
attended all five calls. From the 24 VA sites, 20 course leaders submitted individual feedback forms after course completion. The other four did not teach the course, and their reasons were: two reported program changes; one changed jobs; one used only the interview tool to enhance an existing class for auditory hallucinations. The course leaders described patient attendance in each group ranging from one to five course participants.

\section{Feedback}

Twenty feedback forms were received (83\%). Per protocol, the names of course leaders were not listed on the feedback forms or on return addresses. Frequencies for each item on the Course Leader Feedback Form are depicted in Table 3. One hundred percent of course leaders providing feedback reported that after teaching the course, they were better able to communicate with patients about the patients' voices, $96 \%$ felt that their understanding of the voice hearing experience improved, $90 \%$ thought the course was a worthwhile experience, and $73 \%$ planned to teach the course again.

Thirty-three course participants provided feedback to their course leaders after completion of the course. Course leaders tallied the de-identified feedback data. Frequencies for each item on the Course Participant Feedback Form are depicted in Table 4. Ninety-four percent would recommend the course to other voice-hearers, $85 \%$ reported being better able to communicate about their voices with staff, $83 \%$ reported feeling safer after telling staff about their harm voices (commands to harm self or others), $70 \%$ felt less alone with their voices, and $66 \%$ reported being better able to manage their voices.

\section{Themes from content analyses.}


Themes from content analyses of training teleconferences and emails are depicted in Table 5. These themes identify the course leaders' descriptions of facilitators and barriers to course implementation.

\section{Discussion}

\section{Objective 1: To educate multidisciplinary mental health clinicians to teach the 10 -session}

course

Previous dissemination efforts successfully taught APNs to teach the course. This project extended dissemination efforts to include training to psychiatric mental health nurses and mental health clinicians from social work, psychology and vocational rehabilitation.

\section{Objective 2: To evaluate feedback from course leaders and course participants}

\section{Course leaders.}

The course leaders' ratings on the Course Leader Feedback Form were highly positive, as depicted in Table 3. These ratings suggest the course leaders valued the skills they gained from teaching the course and patient benefits from course completion.

\section{Course participants.}

The course participants' ratings on the Course Participant Feedback Form were also very positive, as depicted in Table 4 . At the end of the course, approximately $66 \%$ of the course participants reported being better able to manage their voices and feeling less alone with their voices. From the course leaders' reports, course participants were surprised others heard voices, that they were not the "only one". Perhaps the support, opportunity to learn new strategies and new terminology for talking about their voices (rating voices on a scale of $0-10$ ) increased comfort and communication skills for those $85 \%$ who reported being better able to communicate with staff about voices. This is a consistent finding from course participants in past work 
(Buffum et al., 2009). The fact that $94 \%$ of course participants would recommend the course to other voice hearers suggests substantial benefits of course attendance.

\section{A Mutual Influence?}

The similarity of course leader and course participant responses on the feedback forms may suggest a possible mutual influence. That is, the high number of course leaders who felt that their understanding and communication about AH improved, may have a relationship to the course participants who felt increased comfort with sharing information about their $\mathrm{AH}$ and felt safer about reporting commands to harm. Additionally, from anecdotal reports, the course leaders reported being motivated by the positive staff-patient interactions, the use of $\mathrm{AH}$ common language, and observations of patient benefits (e.g., communicating with others about their $\mathrm{AH})$.

Another observed mutual influence was between project trainers and course leaders. Course leaders valued the exposure to the project trainers (the original researchers) and vice versa. Over time, feedback from course leaders who have taught the 10 -session course has led to many course improvements. For example, based on course leader feedback, the AHIG was shortened to increase clinical utility. The Course Leader Feedback Form was revised and shortened to increase clarity and greater likelihood of patient completion.

\section{Facilitators and Barriers.}

A strong facilitator for integrating the course into practice was the perceived patient benefit. As Fortney et al. (2012) reported, a key critical feature of implementation is determining whether the innovation improves patient outcomes. Perhaps observable patient benefit influenced course leaders' feedback/evaluations of teaching the 10-session course. Between 90 and $100 \%$ of course leaders reported a positive experience with teaching the course and 
improved understanding and communication with patients about their voices. Yet, only $73 \%$ of the course leaders planned to teach the course again. Course leaders explained multiple practical reasons as barriers for not repeating the 10-session course: job change, role change, lack of time, too little space and insufficient setting-specific resources or support (e.g., staff shortage, existing full program curriculum, leadership absent or in development). Examples of needed support

include compensated release time for course preparation and dedicated space for both conducting the course and storing supplies and confidential paperwork.

\section{Was theory useful for this project?}

The VA QUERI model provided important key elements that guided the project trainers' actions in educating multidisciplinary course leaders to teach the course. Specifically, the partnership between project trainers and clinicians enabled sharing experiences, operationalization of the Treatment Manual specific to clinicians' programs, and consistency among course leaders in teaching strategies and evaluating outcomes. Another critical element was mentoring clinicians to become influential facility-based course leaders. Examples of leadership included gaining organizational support for teaching the course, including other staff and supporting future integration of the course into clinical practice. Effectiveness of translation was demonstrated by the course leaders' positive reports of their own growth about working with voice hearers and their observations of improved patient comfort when communicating about their voices.

Rogers' theory enabled our understanding of types of adopters (e.g., early adopters, late, laggards), processes of implementation, and variations in styles of implementation. We were able to assess each course leader's individual process of adoption and individualize our teaching methods to meet specific needs. For example, some course leaders described a need for 
assistance from their program's leadership. Acting in a consultative role, the project trainers facilitated problem-solving for course leaders to address with their program's leadership issues such as space-related needs, concerns about fitting the course into the program curriculum and staffing the course. Through the venue of teleconferences and emails for interactive and continuous sharing of experiences, contributors (including the project trainers) expanded course leaders' education about the course, provided support, reinforced enthusiasm, and helped problem-solve issues related to course implementation.

\section{Limitations}

Project limitations include the small sample sizes of course leaders and course participants. Data are limited to those who submitted feedback forms. Information is not known about those course leaders and course participants who did not complete some or all of the feedback forms.

\section{Implications for Practice}

The course can be easily adapted for use in a wide range of mental health outpatient settings. This adaptability added to course leaders' comfort in making modifications specific for their settings. Course leaders who repeated the course made modifications based on what they had previously learned. For example, one course leader added 30 minutes to each session to enable a focus on relaxation and enhanced discussion of experience with strategies. Course participant feedback was positive for those participating in courses with modifications.

Not all course adaptations were successful. For example, one course leader tried a semiopen group approach where course participants could drop in. The course leader reported that course participants were not committed and viewed attendance as optional. This setting did not usually offer psychoeducational courses as part of their mental health recovery program. 
Unfamiliarity with the relationship between class attendance and symptom improvement may have also contributed to low patient participation.

In mental health outpatient settings where courses are usually part of their programs, the 10 -session course can be a good fit. In those settings, the culture of offering and attending courses is an expectation for staff and patients, respectively. The 10-session course can become part of the curriculum and offered on a regular basis.

The course tools are useful for staff to discuss with patients whose AH symptoms have never been clearly described or evaluated in detail. For example, teaching patients to use the CAHQ helps establish a common language for describing their AH characteristics (i.e. frequency, loudness, control, tone, clarity, distractibility and distress); and the UVS enables rating of intensity of their $\mathrm{AH}$ and assessment of commands to harm and intent to act on those commands. Likewise, interviewing patients with the AHIG promotes a shared understanding of the $\mathrm{AH}$ experience unique to the individual, who may be sharing information about their voices for the first time. Such interaction is highly gratifying and motivating for both staff and patients.

\section{Future Directions}

\section{Partnerships.}

Advancing and evaluating partnerships among the disciplines in order to implement evidence-based clinical innovations needs further investigation. Advanced practice nurses and psychiatric mental health nurses are ideally situated to lead collaborative efforts, communicate and educate patients and families, and individualize care. Mental health clinicians from psychology, social work, psychiatry and other disciplines offer unique perspectives, organizational leadership and skill sets for group facilitation. Future investigations could address how multidisciplinary teams benefit skill exchange, types and numbers of resources, knowledge 
expansion, support for making change, and patient and staff outcomes. Future dissemination of the 10 -session course could also evaluate the facilitators and barriers to collaborative multidisciplinary co-leadership.

\section{Balancing modifiability and standardization of the 10-session course.}

The 10-session course has been modified over time to accommodate specific settings, cultures, populations, and time frames (Buffum et al., 2009; Kanungpairn, Sitthimongkol, Wattanapailin \& Klainin, 2007). While modifiability of the course is of paramount clinical value and can enhance generalizability, standardization of the course is equally important to demonstrate valid patient benefits (Santacroce, Maccarelli \& Grey, 2004).

Standardization of the course can be achieved by enhancing intervention fidelity. Horner, Rew and Torres (2006) describe three ways that intervention fidelity can be enhanced: 1) developing a treatment manual, 2) providing training sessions for course leaders, and 3) using intervention monitoring tools. The trainers (original researchers) have incorporated two of these methods in the research design of this dissemination project. First, they developed the Treatment Manual that provided standardization of content and detailed descriptions of all course essentials about content and processes; this enabled consistency of dosing (frequency of classes, duration of classes and interval between classes), delivery of the intervention (specified content including amount of time for each topic) and practice of the strategies outside of class that allowed course participants to enact in real life what was learned in class. Second, this Treatment Manual was used to provide training for course leaders' preparation to deliver course content and manage process issues that include developing trust and handling difficult issues.

\section{Conclusion}


The authors' previous work disseminating the 10 -session course established that advanced practice nurses can successfully teach this structured course (Buffum, et al., 2009). This dissemination project demonstrated that other mental health clinicians can also be taught to teach the course and achieve similar improvements in patient outcomes.

Dissemination of research findings is essential if we are to achieve a goal that 90 percent of clinical decisions will be evidence based (Melnyk, Fineout-Overholt, Gallagher-Ford, \& Kaplan, 2012). Utilizing the theoretical tenets of VA QUERI and Rogers' stages of innovation adoption to guide the process of dissemination, the project trainers taught the 10 -session course to 24 VA sites. The partnership of researcher-clinician has demonstrated value for improving the course's clinical utility, flexibility and feasibility. Other mutually influential relationships included course leader-course participant and course leader-project trainer.

These partnerships are one of QUERI's critical features and highlight the value of using theory to guide dissemination. With patient benefit as the highest priority, such partnerships offer great opportunities for implementing evidence-based programs that can address care of mental health patients who suffer from distressing $\mathrm{AH}$. 


\section{References}

Buccheri, R., Trygstad, L., \& Buffum, M. (2010). Treatment Manual: Guidelines for Teaching the 10-Session Behavioral Management of Auditory Hallucinations Course. Unpublished treatment manual.

Buccheri, R., Trygstad, L., \& Dowling, G. (2007). Behavioral management of command hallucinations to harm in schizophrenia. Journal of Psychosocial Nursing and Mental Health Services, 45(9), 46-54.

Buccheri, R., Trygstad, L., Dowling, G., Hopkins, R., White, K., Griffin, J.J., et al. (2004). Longterm effects of teaching behavioral strategies for managing persistent auditory hallucinations in schizophrenia. Journal of Psychosocial Nursing and Mental Health Services, 42(1), 18-27.

Buffum, M.D., Buccheri, R., Trygstad, L., Gerlock, A.A., Birmingham, P., Dowling, G.A., \& Kuhlman, G. (2009). Behavioral management of auditory hallucinations. Journal of Psychosocial Nursing and Mental Health Services, 47(9), 32-40.

Fortney J, Enderle M, McDougall, S., Clothier, J., Otero, J., Altman, L., \& Curran G. (2012). Implementation outcomes of evidence-based quality improvement for depression in VA community based outpatient clinics. Implementation Science. 7(30). doi:10.1186/17485908-7-30.

Gerlock, A.A., Buccheri, R., Buffum, M.D., Trygstad, L., \& Dowling, G. (2010). Responding to command hallucinations to harm: the unpleasant voices scale and harm command safety protocol. Journal of Psychosocial Nursing and Mental Health Services, 48(5), 2633. doi: 10.3928/02793695-20100304-03. 
Horner, S., Rew, L., \& Torres, R. (2006). Enhancing intervention fidelity: A means of strengthening study impact. Journal for Specialists in Pediatric Nursing, 11(2), 80-89.

Kanungpairn, T., Sitthimongkol, Y., Wattanapailin, A. \& Klainin, P. (2007). Effects of a symptom management program on auditory hallucinations in Thai outpatients with a diagnosis of schizophrenia: a pilot study. Nursing and Health Sciences, 9, 34-39.

Melnyk, B.M., Fineout-Overholt, E., Gallagher-Ford, L. \& Kaplan, L. (2012). The state of evidence-based practice in U.S. nurses. Critical implications for nurse leaders and educators. Journal of Nursing Administration, 42(9), 410-417.

Rogers, E.M. (2003). Diffusion of innovations (5th ed.). New York: Free Press.

Sanson-Fisher, R.W. (2004). Diffusion of innovation theory for clinical change. Medical Journal of Australia, 180, S55-S56.

Santacroce, S., Maccarelli, L.M., Grey, M. (2004). Intervention fidelity. Nursing Research, $53(1), 63-66$.

Stetler, C.B., McQueen L., Demakis, J., Mittman, B.S. (2008). An organizational framework and strategic implementation for system-level change to enhance research-based practice: QUERI Series. Implementation Science. 3(30). doi: 10.1186/1748-5908-3-30. 
Figure 1

Sample Flyer

\section{Managing Voices Course}

We are seeking people who are interested in attending a 10-session course that teaches how to manage voices.

Benefits of Taking the Course

(-) Realize others hear voices and that you are not alone

(-Learn new coping strategies for managing disturbing voices

- Learn new communication skills

(2Learn new ways to increase relaxation

(๑) Receive certificate of participation

Contact at if you would like to participate.

Date and time of classes:

Location of classes: 
Table 1. Course Leader Activities Characterizing Rogers Stages of Innovation Adoption Theory

\begin{tabular}{|c|c|}
\hline $\begin{array}{l}\text { Stages of Rogers' } \\
\text { Theory }\end{array}$ & $\begin{array}{l}\text { Course Leader Activities Corresponding to Rogers' Stages } \\
\text { of Innovation Adoption }\end{array}$ \\
\hline $\begin{array}{l}\text { Stage I. Knowledge- } \\
\text { when the individual is } \\
\text { exposed, learns and } \\
\text { understands the } \\
\text { innovation }\end{array}$ & $\begin{array}{l}\text { - Attended an introductory session outlining the evidence } \\
\text { about the effectiveness of } 10 \text {-session course ( } 30 \text { min) and } \\
\text { workshop about how to teach the } 10 \text {-session course ( } 90 \\
\text { min) — both presentations at VA Psychosocial Rehabilitation } \\
\text { and Recovery Conferences } \\
\text { - Self-selected participation after attending presentations at VA } \\
\text { conference or having heard about 10-session course for } \\
\text { managing voices from a VA colleague } \\
\text { - Responded to email communication outlining project trainers' } \\
\text { scheduled plans } \\
\text { - Attended 1st training conference call and stated own potential } \\
\text { date for teaching course } \\
\text { - Evaluated appropriateness of the course for patient } \\
\text { population in own settings } \\
\text { - Enrolled in study by providing response to information letter } \\
\text { - Obtained training materials (e.g., articles, a training DVD, a } \\
\text { copy of the Treatment Manual with instruments; CD for } \\
\text { relaxation) }\end{array}$ \\
\hline Stage II. Persua & - Assessed openness to conducting the course in own setting; \\
\hline
\end{tabular}




\begin{tabular}{|c|c|}
\hline $\begin{array}{l}\text { when the individual } \\
\text { develops a favorable } \\
\text { attitude about the } \\
\text { innovation }\end{array}$ & $\begin{array}{l}\text { discussed needs for co-leader, space, time, support for } \\
\text { implementation in the treatment program } \\
\text { - Established alignment with the program's specific outpatient } \\
\text { mission and goals }\end{array}$ \\
\hline $\begin{array}{l}\text { Stage III. Decision-- } \\
\text { when the individual } \\
\text { begins activities that } \\
\text { lead to a choice to reject } \\
\text { or adopt }\end{array}$ & $\begin{array}{l}\text { - Determined others' commitment for training, co-leading, } \\
\text { helping organize the } 10 \text {-session course } \\
\text { - Described plans for implementation in own setting on } \\
\text { training calls } \\
\text { - Plan for training other staff: watching the DVD; encouraging } \\
\text { staff attendance at calls; reviewing and using the Treatment } \\
\text { Manual; reviewing the relaxation CD, instruments, and } \\
\text { individual practice records }\end{array}$ \\
\hline $\begin{array}{l}\text { Stage IV. } \\
\text { Implementation-when } \\
\text { the individual actually } \\
\text { begins the innovation }\end{array}$ & $\begin{array}{l}\text { - Established conference call schedule; posted it for staff and } \\
\text { personally invited staff to be on the calls; participated in calls } \\
\text { or informed project trainers of absences } \\
\text { - Conducted the course with course participants } \\
\text { Defined and planned the adaptations specific to site and } \\
\text { setting (e.g., numbers of patients, conflicting courses, } \\
\text { availability of co-leader) } \\
\text { - Committed to encouraging patient completion of all practice } \\
\text { records, symptom assessment forms (e.g., Unpleasant Voices } \\
\text { Scale/0-10 [UVS/0-10]); Characteristics of Auditory } \\
\text { Hallucinations Questionnaire [CAHQ]) }\end{array}$ \\
\hline
\end{tabular}




\begin{tabular}{|c|c|}
\hline & $\begin{array}{l}\text { - Asked course participants to complete feedback form that } \\
\text { evaluated helpfulness of the course } \\
\text { - Course leader evaluated helpfulness of the course and } \\
\text { solicited feedback from other staff }\end{array}$ \\
\hline $\begin{array}{l}\text { Stage V. } \\
\text { Confirmation-when } \\
\text { the individual decides } \\
\text { to continue, reject, or } \\
\text { delay adoption }\end{array}$ & $\begin{array}{l}\text { - Course leader discussed future with program leadership, } \\
\text { sharing that course benefitted patients and staff enjoyed } \\
\text { teaching the course } \\
\text { - Course leaders decided, based on own responses and course } \\
\text { participants' anecdotal responses, whether benefits warranted } \\
\text { including the course in the curriculum } \\
\text { - Discussed with other staff and program leadership about re- } \\
\text { organizing the planned curriculum to include the 10-session } \\
\text { course } \\
\text { - Examined alternatives or changes in how the course content } \\
\text { would be used, such as creating an additional support group } \\
\text { for maintenance of learnings, or using only specific elements } \\
\text { of the course for individual interaction } \\
\text { - Enhanced and customized the course with creative ideas }\end{array}$ \\
\hline
\end{tabular}


Table 2. List of Strategies Taught in the 10-Session Behavioral Management of Auditory Hallucinations Course

\begin{tabular}{|l|}
\hline Name of Strategy \\
\hline 1. symptom self-awareness \\
\hline 2. talking with someone (not necessarily about the voices, talk about anything) \\
\hline 3. listening to music \\
\hline 4. watching television or watching something else \\
\hline 5. saying "stop", ignoring the voices, or not doing what they command \\
\hline 6. using one or two earplugs \\
\hline 7. using relaxation exercises \\
\hline 8. keeping busy, doing something enjoyable (going for a walk, helping others) \\
\hline 9. communicating about taking prescribed medications and not using drugs and/or \\
alcohol
\end{tabular}



Table 3. Frequency of Course Leader Feedback Responses ( $\mathrm{n}=20)$

\begin{tabular}{|l|l|}
\hline Question & Results \\
\hline Has your understanding of the voice hearing & Yes $16(96 \%)$ \\
experience improved? $(\mathrm{n}=17)$ & $16 \%)$ \\
\hline $\begin{array}{l}\text { Are you better able to communicate with patients } \\
\text { about their voices? (n=17) }\end{array}$ & Yes $17(100 \%)$ \\
\hline $\begin{array}{l}\text { Was teaching this course a worthwhile experience } \\
\text { for you? (n=20) }\end{array}$ & Yes $18(90 \%)$ \\
\hline Do you plan to teach the course again? (n=15) & Yes $11(70 \%)$ \\
\hline
\end{tabular}


Table 4. Frequency of Course Participant Feedback Responses $(n=33)$

\begin{tabular}{|c|c|}
\hline Question & Results \\
\hline Better able to manage voices? $(n=32)$ & $\begin{array}{l}\text { Yes: } 21(66 \%) \\
\text { No: } 11(34 \%)\end{array}$ \\
\hline $\begin{array}{l}\text { Better able to communicate about voices } \\
\text { with staff? }(n=33)\end{array}$ & $\begin{array}{l}\text { Yes: } 28(85 \%) \\
\text { No: } 5(16 \%)\end{array}$ \\
\hline $\begin{array}{l}\text { Feeling less alone with your voices? } \\
(\mathrm{n}=33)\end{array}$ & $\begin{array}{l}\text { Yes } 23(70 \%) \\
\text { No: } 10(30 \%)\end{array}$ \\
\hline $\begin{array}{l}\text { If you hear harm voices, do you feel safer } \\
\text { after telling staff about them? }(\mathrm{n}=32)\end{array}$ & $\begin{array}{l}\text { Do not hear harm voices: } 9(28 \%) \\
\text { Hear harm voices: } 23(82 \%) \\
\text { Of the } 23 \text { who hear harm voices: } \\
\text { Yes, feel safer: } \quad 19(83 \%) \\
\text { No, do not feel safer: } 4(17 \%)\end{array}$ \\
\hline $\begin{array}{l}\text { Would you recommend this course to } \\
\text { others who hear voices? }(n=33)\end{array}$ & $\begin{array}{l}\text { Yes: } 31(94 \%) \\
\text { No: } 2 \quad(6 \%)\end{array}$ \\
\hline
\end{tabular}


Table 5. Themes from Course Leader Feedback about Facilitators and Barriers to Teaching the Course

\begin{tabular}{|c|c|}
\hline $\begin{array}{l}\text { Themes identified } \\
\text { as facilitators to } \\
\text { teaching the } \\
\text { course }\end{array}$ & Examples \\
\hline $\begin{array}{l}\text { Conference calls } \\
\text { were viewed as } \\
\text { supportive }\end{array}$ & $\begin{array}{l}\text { "[Conference calls were] helpful, gave confidence for educating staff and } \\
\text { patient participants, provided support for individual lone facilitators so that } \\
\text { they did not feel isolated." }\end{array}$ \\
\hline $\begin{array}{l}\text { Course leaders' } \\
\text { experienced patient } \\
\text { benefit (Open } \\
\text { discussion of AH: } \\
\text { safety and comfort } \\
\text { in talking freely) }\end{array}$ & $\begin{array}{l}\text { "I think members in our group enjoyed the freedom to talk about their } \\
\text { voices without fear of being immediately hospitalized." } \\
\text { "We learned that most patients, in spite of their frequent contacts with } \\
\text { providers, never had the opportunity to speak about their symptoms in such } \\
\text { details. " } \\
\text { "Patients are overwhelmingly positive about having a group like this so that } \\
\text { they could speak about their AH symptoms, most of them for the first time } \\
\text { with others. It is destigmatizing and comforting; these group members } \\
\text { have known each other for many years and have come to groups together in } \\
\text { the past. It is very interesting to know that this group allows them to talk } \\
\text { freely about their symptoms of schizophrenia. That is by itself an } \\
\text { accomplishment." } \\
\text { "Veterans feel safe, connected with those suffering from the same } \\
\text { condition, establish friendships, increased awareness, and learned useful } \\
\text { strategies." }\end{array}$ \\
\hline Course leaders' & "One quarter had 2 extra weeks in it. We used the extra time for assessment \\
\hline
\end{tabular}




\begin{tabular}{|c|c|}
\hline $\begin{array}{l}\text { freedom to develop } \\
\text { site-specific } \\
\text { changes (Creative } \\
\text { ideas in adapting } \\
\text { course to meet } \\
\text { needs of patients } \\
\text { and site) }\end{array}$ & $\begin{array}{l}\text { and review at beginning and end." } \\
\text { "We offered } 2 \text { sessions per strategy, running the course over } 20 \text { sessions. } \\
\text { Creating } 2 \text { classes with one focused on the strategy gave practice and } \\
\text { homework time." } \\
\text { One course leader described using art drawings for the participants to show } \\
\text { size of voice next to size of themselves. } \\
\text { To bring evidence-based practice to staff, one course leader conducted a } \\
\text { continuing education program for social workers that included having a Vet } \\
\text { present his experience in the AH group. } \\
\text { "We had no problems getting patients to do homework---and didn't use } \\
\text { incentives other than positive verbal feedback." }\end{array}$ \\
\hline $\begin{array}{l}\text { Course leaders' } \\
\text { observed patient } \\
\text { positive reactions } \\
\text { (Vets helping each }\end{array}$ & $\begin{array}{l}\text { "This Vet came to group one day and asked about delusions; discussion } \\
\text { ensued about delusions versus AH, definitions. Vet began seeing that the } \\
\text { voice isn't real. Began to feel he could manage. His case manager was } \\
\text { surprised about the Vet's openness about problem-solving the delusion and } \\
\text { voice and that he could make the voice less bothersome." } \\
\text { "For the strategy about telling voice to be quiet, one Vet joked to another to } \\
\text { help with talking back. 'Why don't you turn back to the voice and } \\
\text { challenge him with, Well, who are you? You're just a voice! How smart } \\
\text { are you?' " } \\
\text { "Like that the Veterans appreciate the course. Vets help each other." }\end{array}$ \\
\hline $\begin{array}{l}\text { Course leaders' } \\
\text { observed new } \\
\text { patient knowledge }\end{array}$ & "Vets realized that symptoms worsen \\
\hline
\end{tabular}




\begin{tabular}{|c|c|}
\hline $\begin{array}{l}\text { (Self-awareness of } \\
\text { what makes AH } \\
\text { worse) }\end{array}$ & \\
\hline $\begin{array}{l}\text { Themes identified } \\
\text { as barriers to } \\
\text { teaching the } \\
\text { course }\end{array}$ & Examples \\
\hline $\begin{array}{l}\text { Course leaders' } \\
\text { excessive work } \\
\text { (Burdensome } \\
\text { paperwork) }\end{array}$ & "Too many questionnaires/forms for both patients and course leaders." \\
\hline $\begin{array}{l}\text { Time constraints } \\
\text { for teaching each } \\
\text { session }\end{array}$ & $\begin{array}{l}\text { "We were always pressed for time because it was not uncommon to have } \\
40 \text { minutes only by the time everyone settled down." }\end{array}$ \\
\hline $\begin{array}{l}\text { Patient dislike of } \\
\text { practice outside } \\
\text { classes (Issue of } \\
\text { course participants } \\
\text { completion } \\
\text { individual practice } \\
\text { records [IPRs]) }\end{array}$ & $\begin{array}{l}\text { "Some Vets are not doing the individual practice records (homework) due } \\
\text { to lack of privacy." } \\
\text { "Vets did not remember to do IPR despite staff reminders." } \\
\text { "Course leaders need more ideas for how to get skills to be practiced } \\
\text { outside of group." }\end{array}$ \\
\hline
\end{tabular}

